\title{
The role of VOC oxidation products in continental new particle formation
}

\author{
A. Laaksonen ${ }^{1,4}$, M. Kulmala ${ }^{2}$, C. D. O'Dowd ${ }^{3}$, J. Joutsensaari ${ }^{1,{ }^{*}}$, P. Vaattovaara ${ }^{1}$, S. Mikkonen ${ }^{1}$, K. E. J. Lehtinen ${ }^{1,4}$, \\ L. Sogacheva' ${ }^{2}$ M. Dal Maso' ${ }^{2}$, P. Aalto ${ }^{2}$, T. Petäjä2 ${ }^{2}$, A. Sogachev², Y. J. Yoon ${ }^{3, * *}$, H. Lihavainen ${ }^{4}$, D. Nilsson ${ }^{5}$, \\ M. C. Facchini ${ }^{6}$, F. Cavalli, ${ }^{6 * * *}$, S. Fuzzi ${ }^{6}$, T. Hoffmann ${ }^{7}$, F. Arnold ${ }^{8}$, M. Hanke ${ }^{8}$, K. Sellegri ${ }^{8, * * * *}$, B. Umann ${ }^{8}$, \\ W. Junkermann ${ }^{9}$, H. Coe $^{10}$, J. D. Allan ${ }^{10}$, M. R. Alfarra ${ }^{10, * * * * *}$, D. R. Worsnop ${ }^{11}$, M. -L. Riekkola ${ }^{12}$, T. Hyötyläinen ${ }^{12}$, \\ and Y. Viisanen ${ }^{4}$ \\ ${ }^{1}$ University of Kuopio, Department of Physics, POB 1627, 70211 Kuopio, Finland \\ ${ }^{2}$ University of Helsinki, Department of Physical Sciences, Helsinki, Finland \\ ${ }^{3}$ National University of Ireland, Galway, Department of Physics, Ireland \\ ${ }^{4}$ Finnish Meteorological Institute, POB 503, 00101 Helsinki, Finland \\ ${ }^{5}$ Stockholm Univ., Dept. of Applied Environmental Science (ITM), Atmospheric Science Unit, 10691, Stockholm, Sweden \\ ${ }^{6}$ Istituto di Scienze dell'Atmosfera e del Clima - CNR, Italy Via Gobetti 101, 40129 Bologna ,Italy \\ ${ }^{7}$ Johannes Gutenberg-University of Mainz, 55128, Mainz, Germany \\ ${ }^{8}$ Max-Planck-Institute for Nuclear Physics, Heidelberg, Germany \\ ${ }^{9}$ Forschungszentrum Karlsruhe, Ins. for Meteorology and Climate Research, IMK-IFU, Garmisch-Partenkirchen, Germany \\ ${ }^{10}$ School of Atmospheric and Environmental Science, University of Manchester, PO Box 88, Manchester, M60 1QD, UK \\ ${ }^{11}$ Aerodyne Research Inc., 45 Manning Road, Billerica, Ma 01821-3976, USA \\ ${ }^{12}$ University of Helsinki, Department of Chemistry, Helsinki, Finland \\ *now at: University of Kuopio, Department of Environmental Sciences, POB 1627, 70211 Kuopio, Finland \\ ** now at: Korea Polar Res. Inst., SongDo Techno Park, 7-50, Songdo-dong, Yeonsu-Gu, Incheon City, 406-840, Korea \\ **** now at: Joint Research Centre, Via E. Fermi, 1, 21020 Ispra, Italy \\ **** now at: Laboratoire de Météorologie Physique (LaMP), Observatoire de Physique du Globe de Clermont-Ferrand \\ (OPGC), UMR 6016 CNRS, France \\ ****** now at: Paul Scherrer Institut, 5232 Villigen, Switzerland
}

Received: 2 May 2007 - Published in Atmos. Chem. Phys. Discuss.: 4 June 2007

Revised: 7 May 2008 - Accepted: 8 May 2008 - Published: 20 May 2008

\begin{abstract}
Aerosol physical and chemical properties and trace gas concentrations were measured during the QUEST field campaign in March-April 2003, in Hyytiälä, Finland. Our aim was to understand the role of oxidation products of VOC's such as mono- and sesquiterpenes in atmospheric nucleation events. Particle chemical compositions were measured using the Aerodyne Aerosol Mass Spectrometer, and chemical compositions of aerosol samples collected with low-pressure impactors and a high volume sampler were analysed using a number of techniques. The results indicate that during and after new particle formation, all parti-
\end{abstract}

Correspondence to: A. Laaksonen (ari.laaksonen@uku.fi) cles larger than $50 \mathrm{~nm}$ in diameter contained similar organic substances that are likely to be mono- and sesquiterpene oxidation products. The oxidation products identified in the high volume samples were shown to be mostly aldehydes. In order to study the composition of particles in the $10-50 \mathrm{~nm}$ range, we made use of Tandem Differential Mobility Analyzer results. We found that during nucleation events, both 10 and $50 \mathrm{~nm}$ particle growth factors due to uptake of ethanol vapour correlate strongly with gas-phase monoterpene oxidation product (MTOP) concentrations, indicating that the organic constituents of particles smaller than $50 \mathrm{~nm}$ in diameter are at least partly similar to those of larger particles. We furthermore showed that particle growth rates during the nucleation events are correlated with the gas-phase MTOP

Published by Copernicus Publications on behalf of the European Geosciences Union. 
concentrations. This indicates that VOC oxidation products may have a key role in determining the spatial and temporal features of the nucleation events. This conclusion was supported by our aircraft measurements of new 3-10 nm particle concentrations, which showed that the nucleation event on 28 March 2003, started at the ground layer, i.e. near the VOC source, and evolved together with the mixed layer. Furthermore, no new particle formation was detected upwind away from the forest, above the frozen Gulf of Bothnia.

\section{Introduction}

Atmospheric nucleation of new aerosol particles has in the recent years received considerable attention (Kulmala, 2003) as it has become evident that, given favourable circumstances, nucleation takes place almost everywhere in the atmosphere (Kulmala et al., 2004), and is potentially an important source of cloud condensation nuclei (Laaksonen et al., 2005, Komppula et al., 2005). Despite extensive research efforts, both experimental and theoretical, many aspects of atmospheric new particle formation remain elusive. Perhaps the most widely accepted theory (Kulmala et al., 2000) postulates that ternary nucleation of sulfuric acid, ammonia and water explains the appearance of thermodynamically stable clusters (TSC) in the $1-2 \mathrm{~nm}$ size range. However, the concentrations of sulfuric acid are generally too low to allow the clusters to grow beyond the $3 \mathrm{~nm}$ detection limit of modern aerosol instruments before they are scavenged during collisions with large aerosol particles.

It is suspected that in the Boreal forest environment, where sulphuric acid concentrations are too low to explain particle growth (e.g. Boy et al., 2005), the vapors causing the condensational growth of the clusters to observable sizes are low vapor pressure organic species whose exact chemical natures are unknown. So far, the experimental evidence of this is scarce: O'Dowd et al. (2002) showed, based on particle growth inside a pulse-height analyzing condensation particle counter, that fresh 3-4 nm particles are likely to contain organics, and recently the particle growth rates were shown to correlate with the product of monoterpene concentration and global radiation (Kulmala et al., 2004), a quantity that is expected to be proportional to the concentration of the condensable organics.

Notwithstanding the challenging questions to resolve in terms of micro-scale or nano-scale processes, there also exist many questions regarding the role of macro-scale features of the events. Some key questions arise: what are the spatial scales and degree of homogeneity of continental nucleation events? Does nucleation and growth occur in the free troposphere or in the boundary layer? Is nucleation primarily driven by the mixing of different air parcels? These questions need to be answered before the relevance of homogeneous nucleation as a source of climatically active aerosol particles and cloud condensation nuclei can be assessed and quantified.

Here, we report results from an intensive field measurement campaign that took place in March-April 2003 in Hyytiälä, Finland. Our results shed light on many of the open questions associated with continental boundary layer nucleation. The campaign, featuring two aircraft and an array of state-of-the-art instrumentation, was a part of the EU-funded project QUEST (Quantification of Aerosol Nucleation in the European Boundary Layer), in which experimental and computational tools were used in a comprehensive and focused manner to elucidate key processes and scales associated with atmospheric nucleation events and to better quantify their contribution to the European aerosol population. The measurement site is situated inside a Scots Pine canopy in a rural area in Southern Finland. More than eleven years of continuous aerosol particle size distribution data in the 3 $500 \mathrm{~nm}$ size range is available from the site, where on average 50-100 nucleation events takes place annually with the frequency of the events peaking in springtime. Below, we present new findings on the nature of the chemical species participating in growth of new particles, and link these findings to the spatial and temporal variability of the nucleation events observed during aircraft measurements.

\section{Experimental}

\subsection{Meteorological and gas phase measurements}

Several meteorological and gas phase parameters are being measured continuously at the Hyytiälä station, including temperature, pressure, relative humidity, wind speed and direction, and $\mathrm{SO}_{2}, \mathrm{NO}, \mathrm{NO}_{\mathrm{x}}, \mathrm{CO}, \mathrm{CO}_{2}, \mathrm{H}_{2} \mathrm{~S}$ and $\mathrm{O}_{3}$ concentrations. Several radiation parameters (UVA, UVB, global radiation, PAR) are also being measured continuously. Wind and radiation parameters are also being measured at different heights from a $75 \mathrm{~m}$ high mast. Detailed information of these measurements is provided in Kulmala et al. (2001).

During the 2003 QUEST campaign, a Chemical Ionization Mass Spectrometer (Sellegri et al., 2005a) was operated between 17-29 March to measure volatile organic compounds. As described by Sellegri et al. (2005b), these compounds included acetone, di- and trimethylamine, monoterpenes, isoprene, methyl vinyl ketone and methacrolein, and monoterpene oxidation products (MTOP).

\subsection{Aerosol measurements}

Aerosol size distributions between $3-500 \mathrm{~nm}$ have been recorded at the Hyytiälä station continuously from the beginning of 1996 (e.g. Kulmala et al., 2001). These measurements are taken from 2 meters' height inside the canopy using a twin Differential Mobility Particle Sizer (DMPS) system. The size distribution is recorded in $10 \mathrm{~min}$ intervals. 
The size distribution of particles larger than $500 \mathrm{~nm}$ is currently measured using an aerodynamic particle sizer (APS).

In order to understand the chemical composition of aerosol particles during events of new particle nucleation and growth, we employed during the 2003 QUEST campaign an array of different techniques capable of resolving different chemical features of particles in varying size ranges. Size resolved impactor samples of particles with sizes between $50 \mathrm{~nm}$ and $10 \mu \mathrm{m}$ were collected during nucleation event days (see Cavalli et al., 2006 for details), and these samples were subsequently analysed for inorganic ions concentrations by ion chromatography and for water-soluble organic carbon (WSOC) content by TOC liquid analyser. Furthermore a functional group analysis of the water-soluble organic compounds was performed by Proton Nuclear Magnetic Resonance, HNMR (Cavalli et al., 2006).

To keep the sampling time short, high volume sampler was employed for the collection of aerosol samples for the subsequent analysis of organic compounds, including MTOP. Sampling conditions and analytical procedures for the determination of organics by LC-MS, GC-MS and GC*GC-FID are described elsewhere (Rissanen et al., 2006; Anttila et al., 2005; Kallio et al., 2006)

A quadrupole type Aerodyne Aerosol Mass Spectrometer (AMS) (Jayne et al., 2000; Jimenez et al., 2003) was used to measure the size and composition of particles between 50 and $700 \mathrm{~nm}$. This instrument used fast thermal desorption $\left(600^{\circ} \mathrm{C}\right.$ oven temperature) and $70 \mathrm{eV}$ electron ionisation and the data analysis techniques described by Allan et al. (2003) and Allan et al. (2004) were employed. Using this configuration, it was possible to quantify the nonrefractory component of the particles, which in practice meant the mass concentrations of organics, sulphate, nitrate and ammonium. The instrument was also able to derive composite mass spectra for the organic fraction. More information on this deployment and the results gained can be found in Allan et al. (2006).

In order to obtain chemical information about smaller particles, we used an Ultrafine Organic Tandem Differential Mobility Analyzer (UFO-TDMA) (Joutsensaari et al., 2001; Vaattovaara et al., 2005) to measure ethanol uptake efficiencies of 10 and $50 \mathrm{~nm}$ sized particles. In this instrument, nearly monodisperse particles of desired size are selected from a dried (at RH of about 3\%) polydisperse ambient aerosol using the first DMA of the TDMA system. These particles are then introduced into air mixed with ethanol vapor (saturation ratio 83\%), and their size change is measured using the second DMA. The growth factor $(G F$, ratio of wet and dry sizes) depends on the solubility of the particle material in ethanol and on the molecular size of the aerosol material (provided that all other molecular properties are the same, particles consisting of smaller molecules will show a larger $G F$ at a given saturation ratio).

Earlier, it has been shown that particles consisting of inorganic salts such as ammonium sulfate and sodium chloride do not grow in ethanol vapour $(G F=1)$ whereas many organic substances show GF's up to $1.4-1.5$ at $50-100 \mathrm{~nm}$ dry sizes (Joutsensaari et al., 2001; Vaattovaara et al., 2005) and up to 1.2 at $10 \mathrm{~nm}$ dry sizes (Vaattovaara et al., 2005). Ammonium bisulfate shows modest growth at 50-100 nm (Vaattovaara et al., 2005; Joutsensaari et al., 2004) but does not grow at $10 \mathrm{~nm}$ (Vaattovaara et al., 2005). Similarly, mixed particles of ammonium bisulfate and sulfuric acid (sulfuric acid mass fractions up to 0.50 ) have $G F$ 's of unity at $10 \mathrm{~nm}$ dry size (Vaattovaara et al., 2005). The decrease of the $G F$ as a function of particle dry size for a given substance is mainly due to the Kelvin effect, increasing the vapor pressure of ethanol in the solution droplets as droplet curvature increases. Information concerning the UFO-TDMA measurements during the 2003 QUEST campaign is available in Petäjä et al. (2005).

\subsection{Aircraft measurements}

A Twin Otter (DHC-6/300 operated by the Geological Survey of Finland) aircraft (C. O'Dowd et al., 2008) and the IMK-IFU microlight, a motorized hangglider (Junkermann, 2001, 2005), were deployed during this campaign in order to obtain information about the regional-scale spatial and temporal features of nucleation events. Both of these carried aerosol, gas and meteorological instrumentation to elucidate the spatial extent of these nucleation events and to try to locate the region of the atmosphere where nucleation first occurred.

One of the strongest nucleation events during the campaign occurred on the 28 March 2003. This coincided with the most extensive aircraft missions, with two Twin Otter flights and a microlight flight in between. The flights were designed to capture boundary layer meteorological structure and existing aerosol concentrations prior to the onset of nucleation and to try to locate the region where nucleation occurred first, and then to follow the evolution of boundary layer and aerosol properties throughout the event.

\section{Results and discussion}

\subsection{Overall aerosol chemistry during the campaign}

When the air originated from continental European directions (southeast to southwest), the composition tended to contain organics, ammonium, nitrate, elemental carbon and anthropogenic tracers such as PAHs. The particles were often $\mathrm{pH}$ neutral (based on the measured ions), and submicron aerosol mass concentrations typically reached several $\mu \mathrm{g} \mathrm{m}^{-3}$. Additionally, the mass spectra of the organic fraction measured by the AMS during continental outbreaks exhibited a signature typical of heavily oxidised organic material, previously measured in other background sites subjected to regional pollution (Topping et al., 2004). The sources of these particulate materials are likely to be processed emissions from within continental Europe. The presence of monoterpene oxidation products such pinic and 
Table 1. Concentrations of oxidation products of $\alpha$-pinene in aerosol samples $\left(\mathrm{ng} / \mathrm{m}^{3}\right)$.

\begin{tabular}{cccc}
\hline Sample & pinon-aldehyde & pinic acid & pinonic acid \\
\hline 22.3.2003, 10:00-12:00 & 73.58 & 0.48 & 1.16 \\
22.3.2003, 12:00-14:00 & 61.39 & 1.38 & 1.15 \\
24.3.2003, 08:00-12:00 & 130.17 & 0.32 & 1.69 \\
24.3.2003, 12:00-16:00 & 139.71 & 1.26 & 1.87 \\
10.4.2003, 09:00-13:00 & 41.22 & 0.20 & 3.69 \\
10.4.2003, 13:00-17:00 & 90.07 & 0.71 & 3.03 \\
\hline
\end{tabular}

cis-norpinonic acids (at around $10 \mathrm{ng} \mathrm{m}^{-3}$ ) in these samples indicates that there are biogenic sources in addition to those of anthropogenic origin.

During the arctic air outbreaks (air masses mostly from northwest-northeast directions), the pre-existing aerosol were often acidic, mainly composed of sulfate with little ammonium. While being the dominant species, the mass concentrations of sulfate were low, typically less than $0.5 \mu \mathrm{g} \mathrm{m}^{-3}$. Organic matter was always present, but this was not accompanied with elemental carbon, indicating that it was probably not of anthropogenic origin.

\subsection{Aerosol chemistry following nucleation events}

By the late evening of most nucleation days the particles were large enough $(>30 \mathrm{~nm})$ to be analyzed by an AMS and possessed enough mass to be distinguishable in the sizeresolved data produced by the AMS (Allan et al., 2006). On each nucleation event recorded, the majority of the mass of growing particles was organic in nature. The growing particles only gave a response in AMS $m / z$ (mass number/electric charge) channels associated with organic species (e.g. $\mathrm{m}$ equal to $43,55,57$ ), confirming that the majority of the mass of the growing particles is organic in nature. The base mass peak was invariably $m / z=43$, which can be produced by both aliphatic chains or oxidized functional groups (Allan et al., 2006). Several mass peaks were present at a relative intensity that had not previously been observed with an AMS (Allan et al., 2006), demonstrating that the nature of the organic matter was significantly different from that observed in either anthropogenic emission dominated or remote environments, and consistent with terpene oxidation products. The overall mass spectral fingerprint was identical in each case for small $(<200 \mathrm{~nm}$ in diameter) and large $(300-700 \mathrm{~nm})$ particles, implying that similar secondary organic species were condensing onto all particles. Further to this, it supports the assumption that the analyses of impactor and filter samples should be generally representative of the condensing organic species, regardless of the sizes of the particles sampled.

A comparison between the H-NMR spectra of the impactor-collected nucleation event aerosols and those of secondary organic aerosol (SOA) generated from $\alpha$-pinene in smog chamber experiments, indicates that, in samples collected during nucleation days when anthropogenic pollution levels were low, the oxidation products of $\alpha$-pinene accounted for $72 \%$ of the total H-NMR signal (Cavalli et al., 2006), corresponding to $51 \%$ of water-soluble organic compounds, on average. This finding allows us to postulate that, $\alpha$-pinene oxidation products (and probably also oxidation products from other monoterpenes) are the most likely species to contribute to the growth of nanometer-sized particles. The AMS mass spectra (Allan et al., 2006) are consistent with the identification of these oxidation products.

Previously it has been shown that interaction of organic acids, for example, pinonic acid, produced by photooxidation of terpenes with other organic or inorganic species present in the atmosphere most probably causes observed growth of new particles over forest (Kavouras et al., 1998). However, results of our investigation indicate that aldehydes are responsible for the aerosol growth at least as much as acids. Previously, Boy et al. (2004) found pinonaldehyde in Hyytiälä aerosol samples. Concentrations of $\alpha$-pinene oxidation products obtained from our samples are presented in Table 1. As can be seen, the concentration of pinonaldehyde is considerably higher than the concentrations of corresponding acids. If the emissions of different terpene compounds is taken in account, the significance of sesquiterpene oxidation products for aerosol growth can be expected to be high. The relative contribution of $\alpha$-pinene oxidation products to SOA formation has been predicted to be on the order of $20 \%$ (Andersson-Sköld et al., 2001). The significance of aldehydes in oxidation of sesquiterpenes, and especially their stability and presence in aerosol samples are confirmed by our most recent results (Parshintsev et al., 2008)

It should be noted, however, that pinonaldehyde has a relatively high vapor pressure, and its presence in high concentrations in the aerosol is difficult to explain without invoking some degree of chemical bonding. It is possible that gasphase pinonaldehyde can adsorp onto quartz filters or absorb in the aerosol collected on the filters during the sampling. However, in our recent experiments the gas-phase components were removed before aerosol collection, but we still found high levels of pinonaldehyde in the aerosol. We therefore do not believe sampling artifact to be the (main) reason for the high levels of pinonaldehyde found in the particle phase. Another possibility is that pinonaldehyde is a degradation product of the extraction/analysis procedure. However, we have used a rather "gentle" extraction method, with no heating of the sample, and cool on-column injection is used in our GC method. Thus, alteration of sample during sample introduction is very unlikely. Taken together, the definitive reason for the appearance of pinonaldehyde in the aerosol sample analysis remains unclear. However, the pinonaldehyde functionality is real - whether as molecular pinonaldehyde in the gas phase, or as a degradation product of the aerosol analysis - showing that efficient terpene oxidation is taking place during nucleation events. 


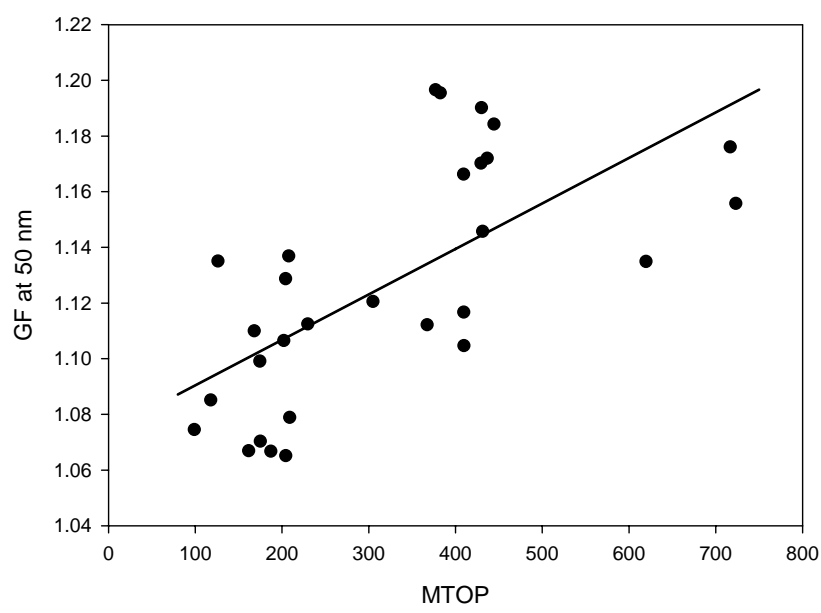

Fig. 1. MTOP concentration (ppt) vs. particle growth factor (wet diameter/dry diameter) of $50 \mathrm{~nm}$ dry particles due to uptake of ethanol. The linear fit is given by $G F=1.07+1.63 e-4 * \mathrm{MTOP}$, $R^{2}=0.44$.

Evidence that freshly nucleated $10 \mathrm{~nm}$ particles contain similar organic substances as the larger particles comes from an examination of the ethanol vapor uptake efficiencies of $10 \mathrm{~nm}$ and $50 \mathrm{~nm}$ particles. Figures 1 and 2 show how the 50 and $10 \mathrm{~nm} G F$ 's measured during nucleation events (i.e. during times when there clearly are freshly formed particles of these sizes present) correlate with gas-phase MTOP whose concentration can be used as a marker for the simultaneous formation of less volatile monoterpene oxidation products. The datapoints represent hourly values where the $G F$ 's are mostly single measurements (i.e. measurements were carried out once per hour) and the MTOP's are means of six tenminute measurements. The measurement error of the $G F$ is \pm 0.01 , and the average standard deviation of the MTOP values is 13 ppt. The correlations are very clear, but importantly they vanish when data measured during non-event periods are included. Note that with the linear fits in Figs. 1 and 2 we do not intend to indicate that high $G F$ 's cannot be found at low MTOP concentrations. Indeed, it is evident from Fig. 2 that such circumstances also occur. Assuming that the $10 \mathrm{~nm}$ particles mostly consist of sulphate and organics, and accounting for the fact that sulphate does not take up ethanol in $10 \mathrm{~nm}$ particles (Vaattovaara et al., 2005), then it could be possible to have high $G F$ 's at low MTOP concentrations provided that the sulphuric acid concentration is low as well. Indeed, examination of our data showed that the high $G F$ datapoints at low MTOP concentrations seen in Fig. 2 are from 19 March, when particle growth was slow (growth rate $1 \mathrm{~nm} / \mathrm{h}$; see Fig. 3 below), implying that the levels of all condensing species were rather low.

Summarizing the above findings, we have 1) inferred detailed information of the chemical nature of condensed organics from the various large particle analyses, 2) shown that

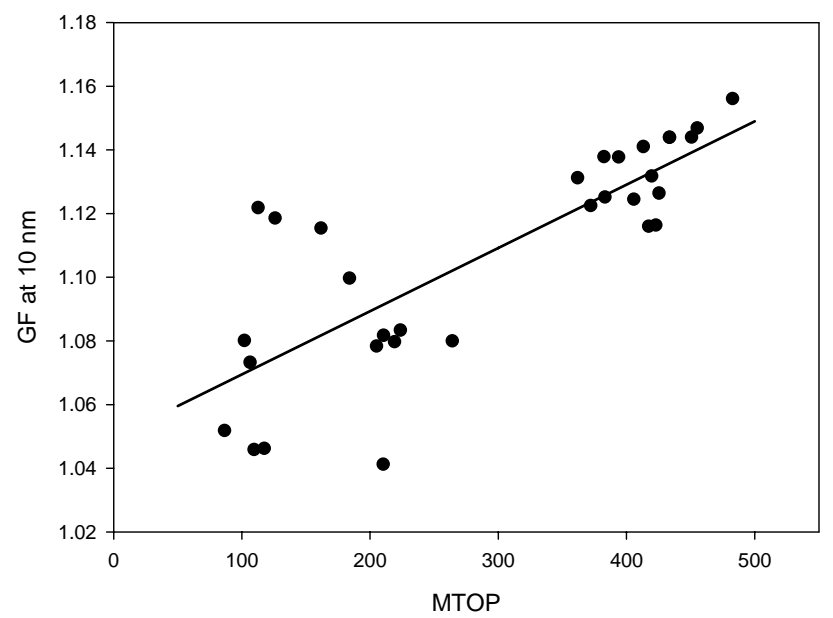

Fig. 2. MTOP concentration (ppt) vs. particle growth factor (wet diameter/dry diameter) of $10 \mathrm{~nm}$ dry particles due to uptake of ethanol. The linear fit is given by $G F=1.05+1.99 e-4 *$ MTOP, $R^{2}=0.64$.

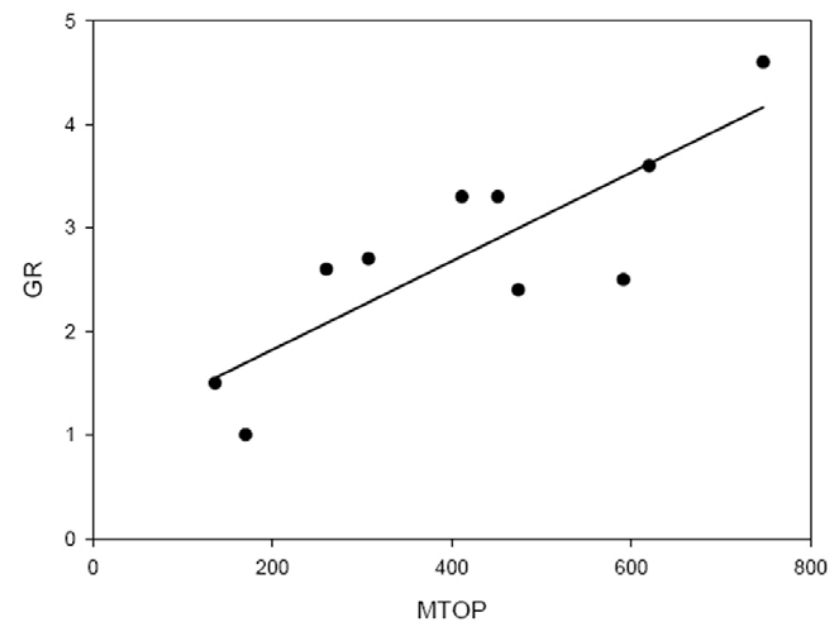

Fig. 3. Particle diameter growth rates $\left(G R, \mathrm{~nm} \mathrm{~h}^{-1}\right)$ during ten different nucleation events vs. gas-phase MTOP concentration (ppt). MTOP values have been averaged over the time interval from which the growth rate was determined. The linear fit is given by $G R=0.97+0.0043^{*} \mathrm{MTOP}, R^{2}=0.965$.

the AMS mass spectra are consistent with the large particle results and that the mass spectra in the largest (below one micron) and in the smallest (below $100 \mathrm{~nm}$ ) size ranges detected by the instrument are similar, and 3) used the OTDMA to show that the ethanol growth factors of $50 \mathrm{~nm}$ and $10 \mathrm{~nm}$ particles are both correlated with MTOP during nucleation events and therefore it is highly likely that they both contain similar organics which can also be found in larger particles.

Figure 3 shows a positive correlation between particle growth rates $(G R)$ during different nucleation events, and gas-phase MTOP concentrations averaged over the events. 


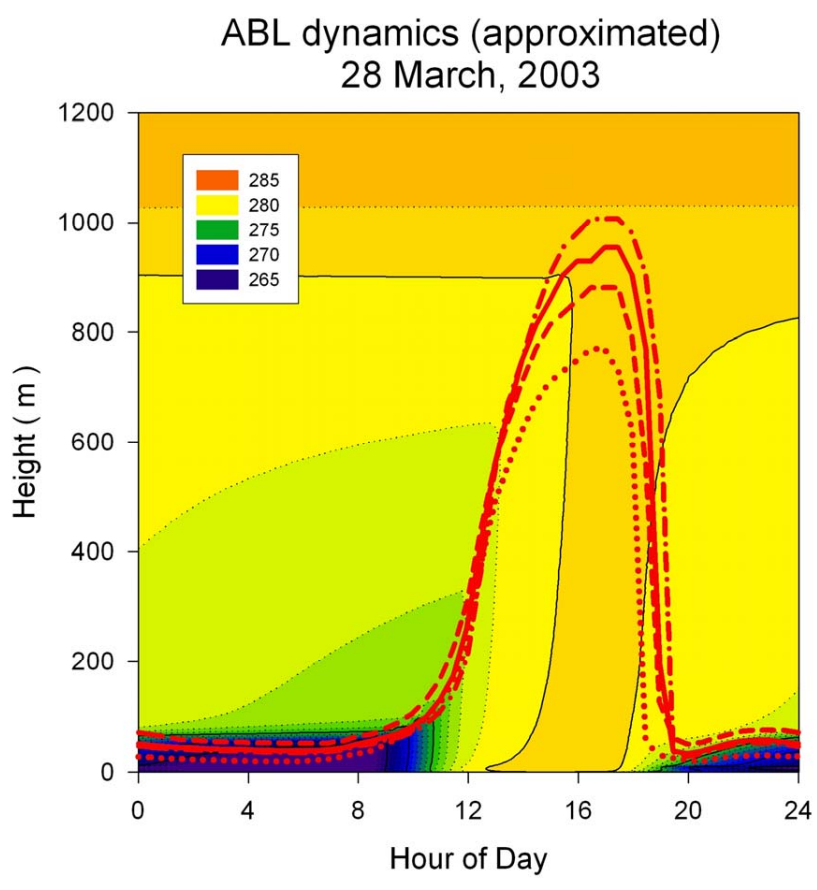

Fig. 4. Evolution of height of mixed layer during 28 March 2003. Dotted line approximates ABL dynamics with bare surface (no vegetation); dashed line with vegetation similar to one at Hyytiäla but with twice less leaf area index (LAI); solid line for Hyytiäla vegetation (pine forest $15 \mathrm{~m}$ height, all side LAI 7.4); dash-dot line with vegetation similar to one at Hyytiäla but with twice higher LAI. Potential temperature field is for Hyytiäla forest and radiation data from Hyytiäla tower. Radiation input was the same in all calculations. Colour indicates potential temperature. See text for additional details.

In stark contrast to observations made in Pittsburgh (Zhang et al., 2004) no such correlation can be seen between the $G R$ and gas phase sulfuric acid concentration. We therefore conclude that oxidation products of $\alpha$-pinene and other monoterpenes are not only present in the freshly nucleated particles at all detectable sizes, but also determine their growth rates and thus their survival probability into a size range where they become optically active and relevant as $\mathrm{CCN}$.

\subsection{Evolution of nucleation event}

The spatial and temporal evolution of the nucleation events depends on two quite different gas phase species: sulphur dioxide, the precursor of $\mathrm{H}_{2} \mathrm{SO}_{4}$ which is likely to be the controlling factor in the nucleation of the smallest stable clusters, and VOC oxidation products which, as shown above, dominate particle growth. $\mathrm{SO}_{2}$ at the Hyytiälä station is mostly long range transported: its residence time is on the order of days, and because there are no strong sources nearby, it has quite uniform concentrations in the mixed layer air. Monoand sesquiterpenes, on the other hand, have shorter lifetime, and they are locally released by trees. As MTOP determine particle growth rates, it is conceivable that observable particle formation is limited to areas close to the mono- and sesquiterpene sources. Demonstrations of this were obtained from aircraft measurements carried out during the measurement campaign

The descent into the aircraft operation area on 28 March 2003 , indicated a decoupled boundary layer structure following a night of significant nocturnal cooling. The boundary layer comprised a mixed layer inversion up to $250 \mathrm{~m}$, a first decoupled mixed layer or residual layer at $300-900 \mathrm{~m}$ and a second residual layer between 900 and $1400 \mathrm{~m}$ where the free troposphere inversion was located. Total particle concentrations in the free troposphere and upper residual layer was of the order of $70-100 \mathrm{~cm}^{-3}$, increasing to $2500-3000 \mathrm{~cm}^{-3}$ at about $600 \mathrm{~m}$ (through the lower residual layer and mixed layer). No nucleation mode particles were encountered during the descent. Following the descent, a series of 10-min horizontal runs (corresponding to a spatial scale of $60 \mathrm{~km}$ ) were conducted at heights between $30 \mathrm{~m}$ and $300 \mathrm{~m}$ above ground level and over fixed ground positions. On the return to the starting ground position, an ascent from the endground position to $1000 \mathrm{~m}$ was conducted, followed by a descent to the start ground position. The first evidence of particle formation was encountered at approximately 09:00 a.m. on the $30 \mathrm{~m}$ horizontal where particle concentrations briefly increased from 3000 to $8000 \mathrm{~cm}^{-3}$. For the next hour, during these runs, more small parcels of air containing nucleation mode particles were encountered and gradually, the whole boundary layer become laden with nucleation mode particles and by 10:50 a.m., peak particle concentrations exceeded $30000 \mathrm{~cm}^{-3}$.

In order to characterise the boundary layer evolution during the morning of 28 March, the mixed layer height was modelled using radiation and wind recorded at different heights from the $75 \mathrm{~m}$ high mast at the Hyytiälä measurement station. Figure 4 shows potential temperature evolution as a function of altitude during the day. We estimated the ABL dynamics using observed data of potential temperature profile in the free atmosphere (O'Dowd et al., 2008). The geostrophical wind was approximated as $5 \mathrm{~m} / \mathrm{s}$. As the surface above which the flights took place is not homogeneous, we calculated the ABL dynamics assuming different types of vegetation, which resulted in some variance (see Fig. 4).

A total of 24 aircraft profiles were conducted to characterise the evolution of the boundary layer aerosol during the nucleation event and to identify where the particles are most likely to be formed. An interpolated composite of particle concentration and evolution through the duration of the three flights is shown in Fig. 5. The data shows that new particles are first formed close to the surface, and that the layer of 3-10 nm particles then evolves together with the growth of the mixed layer. (A careful examination of Figs. 4 and 5 would appear to suggest that the particle plume extends above the mixed layer after about 11 a.m.; however individual profiles shown in O'Dowd et al. (2008), confirm that 


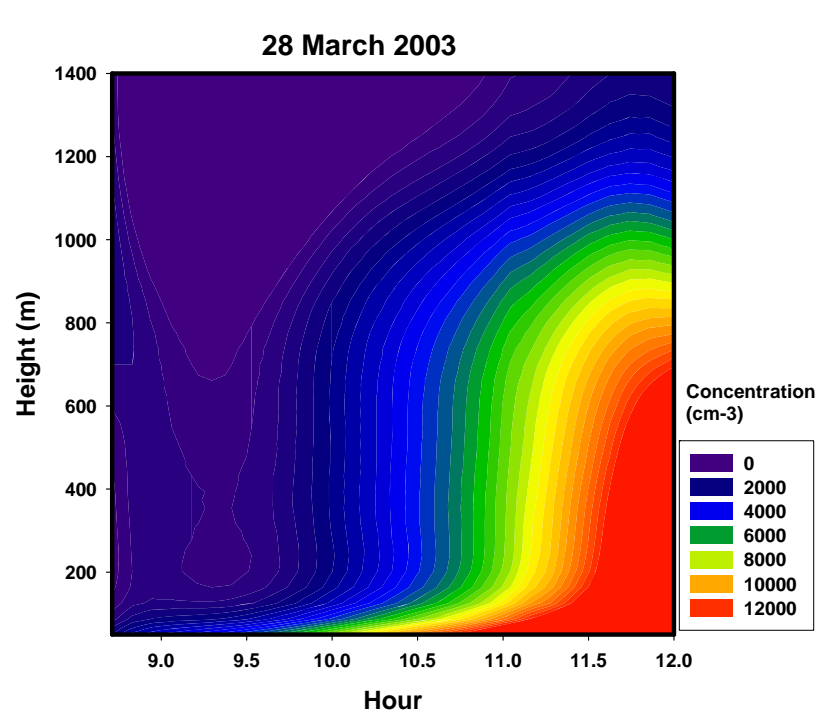

Fig. 5. Interpolated contour plot of total particle $(3 \mathrm{~nm}-1 \mu \mathrm{m})$ concentration variation with height and time of day. The first occurrence of particle production is seen at the lowest levels after which they gradually fill the whole mixed layer.

the particle plume was all the time within the mixed layer. Apparently, the regional variability of the boundary layer structure was larger than suggested by Fig. 4, presumably due to different heat fluxes over lake and canopy surfaces. One should also note that the apparent "smoothness" of the aerosol abundance shown in Fig. 5 is partly caused by averaging over many profiles and by contouring artifacts in this type of plot).

As noted above, there are no strong $\mathrm{SO}_{2}$ sources nearby which could cause $\mathrm{SO}_{2}$ concentrations to decrease uniformly with height. Furthermore, sulphuric acid concentrations in Hyytiälä are generally so low that they can only explain a minor fraction of observed particle growth (e.g. Boy et al., 2005). Taken together, these facts demonstrate that monoand sesquiterpenes, rather than $\mathrm{SO}_{2}$, regulate the evolution of the fresh particle concentrations.

A further demonstration of the canopy influence was obtained from a horizontal flight from the Hyytiälä area to the coast and out over the Gulf of Bothnia (thus moving upwind of the forest canopy). No nucleation was observed over the frozen sea once out of the forest canopy region, showing that production of particles with diameters larger than $3 \mathrm{~nm}$ is confined to regions influenced by the canopy.

\section{Conclusions}

Our aim during the 2003 QUEST campaign was to obtain extensive chemical information of the composition of particles in the widest possible size range, and to use aircraft in characterising the spatial and temporal evolution of nucleation events. In order to study aerosol chemistry, we used an array of techniques including aerosol mass spectrometry, several analytical techniques for aerosol samples, and tandem differential mobility analysis. In this way we were able to obtain information of similarities in the chemical features of particles in the $10 \mathrm{~nm}-10 \mu \mathrm{m}$ size range during and after nucleation events.

During nucleation events, the aerosol chemical characteristics as determined from impactor and filter samples were seen to be consistent with AMS mass spectra. Ethanol growth factors of 10 and $50 \mathrm{~nm}$ particles recorded during nucleation events correlated with gas phase MTOP concentrations, indicating that their organic compositions had similar features. Our results indicate that following nucleation, oxidation products of monoterpenes and possibly also sesquiterpenes are condensing on particles of all sizes in measurable quantities. Further, the correlation between gas-phase MTOP and particle growth rates indicates that the VOC oxidation products dominate particle growth. This is reflected in our aircraft results, which show that the first observable particles in the start of the nucleation event emerge close to the VOC source, in this case the forest canopy. As SOA has been very widely observed in other non-boreal environments, the growth of freshly formed particles to $\mathrm{CCN}$ active sizes may well be governed by the availability and composition of the SOA material available in that environment.

Acknowledgements. This work was supported by the European Commission under contract EVK2-CT2001-00127 (QUEST) and by the Academy of Finland.

Edited by: J. G. Murphy

\section{References}

Allan, J. D., Jimenez, J. L., Williams, P. I., Alfarra, M. R., Bower, K. N., Jayne, J. T., Coe, H., and Worsnop D. R.: Quantitative sampling using an Aerodyne aerosol mass spectrometer - 1. Techniques of data interpretation and error analysis, J. Geophys. Res., 108, 4090, doi:10.1029/2002JD002358, 2003.

Allan, J. D., Coe, H., Bower, K. N. Alfarra, M. R., Delia, A. E., Jimenez, J. L., Middlebrook, A. M., Drewnick, F., Onasch, T. B., Canagaratna, M. R., Jayne, J. T., and Worsnop, D. R.: A generalised method for the extraction of chemically resolved mass spectra from Aerodyne aerosol mass spectrometer data, J. Aerosol. Sci., 35, 909-922, 2004.

Allan, J. D., Alfarra, M. R., Bower, K. N., Coe, H., Jayne, J. T., Worsnop, D. R., Aalto, P. P, Kulmala, M., Hyötyläinen, T., Cavalli, F., and Laaksonen, A.: Size and composition measurements of background aerosol and new particle growth in a Finnish forest 
during QUEST 2 using an Aerodyne Aerosol Mass Spectrometer, Atmos. Chem. Phys., 6, 315-327, 2006,

http://www.atmos-chem-phys.net/6/315/2006/.

Andersson-Sköld, Y. and Simpson, D.: Secondary organic aerosol formation in northern Europe: A model study, J. Geophys. Res., 106, 7357-7374, 2001

Anttila, P., Hyötyläinen, T., Heikkilä, A., Kulmala, M., and Riekkola, M.-L.: Determination of organic acids in aerosol particles from a coniferous forest by liquid chromatography-mass spectrometry, J. Sep. Sci., 28, 337-346, 2005.

Boy, M., Petäjä, T., DalMaso, M., Rannik, Ü, Rinne, J., Aalto, P., Laaksonen, A., Vaattovaara, P., Joutsensaari, J., Hoffmann, T., Warnke, J., Apostolaki, M., Stephanou, E. G., Tsapakis, M., Kouvarakis, A., Pio, C., Carvalho, A., Römpp, A., Moortgat, G., Spirig, C., Guenther, A., Greenberg, J., Ciccioli, P., and Kulmala, M.: Overview of the field measurement campaign in Hyytiälä, August 2001 in the framework of the EU project OSOA, Atmos. Chem. Phys., 4, 657-678, 2004, http://www.atmos-chem-phys.net/4/657/2004/.

Boy, M., Kulmala, M., Ruuskanen, T. M., Pihlatie, M., Reissell, A., Aalto, P. P., Keronen, P., Dal Maso, M., Hellen, H., Hakola, H., Jansson, R., Hanke, M., and Arnold, F.: Sulphuric acid closure and contribution to nucleation mode particle growth, Atmos. Chem. Phys., 5, 657-678, 2005,

http://www.atmos-chem-phys.net/5/657/2005/.

Cavalli, F., Facchini, M. C., Decesari, S., Emblico, L., Mircea, M., Jensen, N. R., and Fuzzi, S.: Size-segregated aerosol chemical composition at a boreal site in southern Finland, during the QUEST project, Atmos. Chem. Phys., 6, 993-1002, 2006, http://www.atmos-chem-phys.net/6/993/2006/.

Jayne, J. T., Leard, D. C. Zhang, X. F., Davidovits, P., Smith, K. A., Kolb, C. E., and Worsnop, D. R.: Development of an aerosol mass spectrometer for size and composition analysis of submicron particles, Aerosol Sci. Technol., 33, 49-70, 2000.

Jimenez, J. L., Jayne, J. T., Shi, Q., Kolb, C. E., Worsnop, D. R., Yourshaw, I., Seinfeld, J. H., Flagan, R. C., Zhang, X., Smith, K. A., Morris, J. W., and Davidovits, P.: Ambient aerosol sampling using the Aerodyne Aerosol Mass Spectrometer, J. Geophys. Res., 108, 8425, doi:10.1029/2001JD001213, 2003.

Joutsensaari, J., Vaattovaara, P., Vesterinen, M., Hämeri, K., and Laaksonen, A.: A novel tandem differential mobility analyzer with organic vapor treatment of aerosol particles, Atmos. Chem. Phys., 1, 51-60, 2001,

http://www.atmos-chem-phys.net/1/51/2001/.

Joutsensaari, J., Toivonen, T., Vaattovaara, P., Vesterinen, M., Vepsäläinen, J., and Laaksonen, A.: Time-resolved growth behavior of acid aerosols in ethanol vapor with a tandem-DMA technique, J. Aerosol Sci., 35, 851-867, 2004.

Junkermann, W.: An ultralight aircraft as platform for research in the lower troposphere: system performance and first results from radiation transfer studies in stratiform aerosol layers and broken cloud conditions, J. Ocean. Atmos. Techn., 18, 934-946, 2001.

Junkermann, W.: The actinic UV-radiation budget during the ESCOMPTE campaign 2001: Results of airborne measurements with the microlight research aircraft D-MIFU, Atmos. Res., 74, 461-475, 2005.

Kallio, M., Jussila, M., Rissanen, T., Anttila, P., Hartonen, K., Reissel, A., Vreuls, R., Adahcour, M., and Hyötyläinen, T.: Comprehensive Two-Dimensional Gas Chromatography Coupled to
Time of Flight Mass Spectrometry $(\mathrm{GC} \times \mathrm{GC}-\mathrm{TOFMS})$ in the Identification of Organic Compounds in Atmospheric Aerosols from Coniferous Forest, J. Chromatogr. A, 1125, 234-243, 2006.

Kavouras, I. G., Mihalopoulos, N., and Stephanou, E. G.: Formation of atmospheric particles from organic acids produced by forests, Nature 395, 683-686, 1998.

Komppula, M., Lihavainen, H., Kerminen, V.-M., Kulmala M., and Viisanen Y.: Measurements of cloud droplet activation of aerosol particles at a clean subarctic background site, J. Geophys. Res., 110, D06204, doi:10.1029/2004JD005200, 2005.

Kulmala, M., Pirjola, L., and Mäkelä. J.M., Stable sulphate clusters as a source of new atmospheric particles.Nature 404, 66-69 (2000).

Kulmala, M., Hämeri, K., Aalto, P. P., Mäkelä, J. M., Pirjola, L., Nilsson, E. D., Buzorius, G., Rannik, Ü., Dal Maso, M., Seidl, W., Hoffmann, T., Janson, R., Hansson, H.-C., Viisanen, Y., Laaksonen, A., and O'Dowd, C.: Overview on the international project on biogenic aerosol formation in the boreal forest (BIOFOR), Tellus, 53B, 324-343, 2001.

Kulmala, M.: How particles nucleate and grow, Science, 302, 10001001, 2003.

Kulmala, M., Suni, T., Lehtinen, K. E. J., Dal Maso, M., Boy, M., Reissell, A., Rannik, Ü, Aalto, P., Keronen, P., Hakola, H., Bäck, J., Hoffmann, T., Vesala, T., and Hari, P.: A new feedback mechanism linking forests, aerosols and climate, Atmos. Chem. Phys., 4, 557-562, 2004, http://www.atmos-chem-phys.net/4/557/2004/.

Laaksonen, A., Hamed, A., Joutsensaari, J., Hiltunen, L., Cavalli, F., Junkermann, W., Asmi, A., Fuzzi, S., and Facchini, M. C.: Cloud condensation nucleus production from nucleation events at a highly polluted region, Geophys. Res. Lett., 32, L06812, doi:10.1029/2004GL022092, 2005.

O’Dowd, C. D., Aalto, P., Hämeri, K., Kulmala, M., and Hoffmann, T.: Atmospheric particles from organic vapours, Nature, 416, 497-498, 2002.

O’Dowd, C. D., Yoon, Y. J., Junkerman, W., Aalto, P., Kulmala, M., Lihavainen, H., and Viisanen, Y.: Airborne measurements of nucleation mode particles II: boreal forest nucleation events, Atmos. Chem. Phys. Discuss., 8, 2821-2848, 2008, http://www.atmos-chem-phys-discuss.net/8/2821/2008/.

Parshintsev, J., Nurmi, J., Kilpeläinen, I., Hartonen, K., Kulmala, M., Riekkola, M.-L.: Preparation of $\beta$-caryophyllene oxidation products and their determination in ambient aerosol samples, Anal. Bioanal. Chem. 390, 913-919, 2008.

Petäjä, T., Kerminen, V.-M., Hämeri, K., Vaattovaara, P., Joutsensaari, J., Junkermann, W., Laaksonen, A., and Kulmala, M.: Effects of $\mathrm{SO}_{2}$ oxidation on aerosol hygroscopicity, Atmos. Chem. Phys., 5, 767-779, 2005,

http://www.atmos-chem-phys.net/5/767/2005/.

Rissanen, T., Kallio, M., Hyötyläinen, T., Kulmala, M., and Riekkola, M.-L.: Characerization of organic compounds in aerosol particles during particle formation in rural atmosphere by GC-MS, Chemosphere, 64, 1185-1195, 2006

Sellegri, K., Umann B., Hanke, M., and Arnold, F.: Deployment of a ground-based CIMS apparatus for the detection of organic gasess in the boreal fores during the QUEST campaign, Atmos. Chem. Phys., 5, 357-372, 2005a, http://www.atmos-chem-phys.net/5/357/2005/.

Sellegri, K., Hanke, M., Umann, B., Arnold, F., and Kulmala, M.: 
Measurement of organic gases during aerosol formation events in the boreal forest atmosphere during QUEST, Atmos. Chem. Phys., 5, 373-384, 2005b, http://www.atmos-chem-phys.net/5/373/2005/.

Topping, D., Coe, H., McFiggans, G., Burgess, R., Allan, J., Alfarra, M.R., Bower, K., Choularton, T.W., Decesari, S., and Facchini, M. C.: Aerosol chemical characteristics from sampling conducted on the Island of Jeju, Korea during ACE Asia, Atmos. Environ., 38, 2111-2123, 2004.
Vaattovaara, P., Räsänen, M., Kuhn, T., Joutsensaari, J., and Laaksonen, A.: A method for detecting the presence of organic fraction in nucleation mode sized particles, Atmos. Chem. Phys., 5, 3277-3287, 2005,

http://www.atmos-chem-phys.net/5/3277/2005/.

Zhang, Q., Stanier, C. O., Canagaratna, M. R., Jayne, J. T., Worsnop, D. R., Pandis, S. N., and Jimenez, J. L.: Insights into Nucleation Burst and Particle Growth in Pittsburgh Based on Aerosol Mass Spectrometry, Environ. Sci. Technol., 38, 47974809, 2004. 